\title{
Performance of Commercial Laying Hen Submitted to Different Debeaking Methods
}

-Author(s)
Oka CH'
Bueno LGF'
Souza SRL"
Balan JAO'
Silva KM"I
Polycarpo GV'
Iwayama LH'v
I São Paulo State University "Júlio de
Mesquita Filho", FCAT, Unesp, Dracena -
São Paulo
" São Paulo State University "Júlio de
Mesquita Filho", FCA, Unesp, Botucatu -
São Paulo
II São Paulo State University "Júlio de
Mesquita Filho", FMVZ, Unesp, Botucatu -
São Paulo;
Iv Hendrix Genetics Ltda, Birigui - São Paulo

\section{Mail Address}

Corresponding author e-mail address Leda Gobbo de Freitas Bueno

Rodovia Comandante João Ribeiro de Barros, km 651, 17900-000, Dracena, São Paulo, Brasil

Tel: $\quad 55$ 18-3821-8173

Email: gobbobueno@gmail.com

\section{-Keywords}

Animal welfare, behavior, stress, egg quality.

\section{ABSTRACT}

Among the several factors required in breeding laying hens, debeaking is a factor that interferes with batch performance and affects animal welfare. Thus, the objective of this study was to evaluate three different debeaking procedures and to verify the best technique to be used. For this, the performance of the birds, the incidence of cannibalism, and in rearing phase, the quality of the eggs were evaluated. Dekalb White birds were distributed in a completely randomized design with three treatments, T1 (infrared radiation debeaking) T2 (hot blade debeaking) and T3 ( $V$ debeaking).The data was submitted to Analysis of Variance and compared by Tukey's test (95\%), using statistical software R. The frequencies of mortality and cannibalism were submitted to the ChiSquare test (Software R). It was observed that mortality was lower with IR debeaking in the breeding phase. Already in the rearing phase, the mortality was similar between the debeaking techniques and the cannibalism was null. The final mean weight $(\mathrm{g})$, mean weight gain $(\mathrm{g})$ and average daily weight gain in the rearing and egg quality variables were higher for $V$ debeaking when compared to other techniques. It is concluded that $\mathrm{V}$-debeaking provides better bird performance, resistance and shell thickness when compared to the infrared radiations and hot blade debeaking, in addition to subjecting the birds to less stress.

\section{INTRODUCTION}

The egg production industry is under intense pressure to eliminate the deboning technique due to the procedure causing acute and chronic pain in the birds. However, elimination of the procedure may negatively impact animal welfare, resulting in an increase in the incidence of aggressive behavior by birds (Guesdon et al., 2007; Denis \& Cheng, 2010; Angevaare et al., 2012) depending on the type of installations and genetics used in breeding. This scenario makes the deboning process a routine and necessary procedure in the egg industry. The technique consists of partial amputation of the upper and lower part of the beak (Denis et al., 2009). It is used in commercial poultry farms, broilers matrices, ducks and turkeys. (Founier et al., 2015).

The debeaking is a procedure that brings benefits to the productive system. However, it subjects the bird to stress, since a great manipulation of all the birds occurs in the lot, which demands care with regard to the length of the beak, blade temperature and especially training of the team that will perform the operation (Fahey et al., 2007). There are several alternatives to perform the debeaking, proposing a better result. Recommendations on the procedure are available in the literature, but there is no standardization of sizes for poultry beaks (Pizzolante et al., 2007).
Submitted: 14/July/2017

Approved: 20/August/2017 
Oka CH, Bueno LGF, Souza SRL, Balan JAO, Silva KM,

Polycarpo GV, Iwayama LH
Performance of Commercial Laying Hen Submitted to Different Debeaking Methods
Conventional hot blade debeaking $(\mathrm{HB})$ is an invasive method, which causes stress and pain, resulting in bird suffering, thus being a reason for resistance to its use. However, it is used in most farms with the objective of improving productive performance (Denis et al., 2009; Denis \& Cheng, 2010).

Less invasive methodologies have been developed, such as the treatment of the beak by infrared radiation $(I R)$, which shows benefits such as the absence of bleeding (Vieira Filho et al., 2016). The technique is performed in the hatchery on the first day of life and is recently being tested (Denis et al, 2009; Denis \& Cheng, 2010). In addition, it is important to note that the presence of infrared light in the corneal tissue of the beak causes necrosis, with the advantage of a gradual fall of the beak, providing adaptability to the new form (Marchant-Forde et al., 2008; Angevaare et al., 2012). Vieira Filho et al. (2016) compared the use of infrared radiation and hot blade with the withdrawal of the second debeaking in the 10th week of life. They verified the absence of cannibalism with the IR debeaking procedure, but they noticed an $8 \%$ decrease in viability on the $63^{\text {rd }}$ week of age of the birds.

Currently, some farms in the Bastos / SP-Brazil region are adopting the method known as $\mathrm{V}$ debeaking, using the Verschuuren debeaker, which performs a cross-cutting movement, with a blade that presents a $\mathrm{V}$-shaped center. Although severe, in the $\mathrm{V}$ debeaking, the second debeaking is not performed. This fact minimizes the severe debeaking being reported in the literature as a precursor of lower zootechnical indexes and pain causing (Pizzolante et al., 2007).

Layers when stressed show aggressive pecking, which leads to cannibalism and consequently an increase in mortality, lower egg production and decrease in egg quality. The fact that the birds are debeaked and the type of debeaking affects the zootechnical indexes and the quality of the eggs (Mertens et al., 2009; Dennis \& Cheng, 2010) makes the technique used to be extremely important (Vieita Flho et al. Al., 2016). According to the above, the study aimed to evaluate three different methods of debeaking in relation to the zootechnical performance and its consequence on egg quality.

\section{MATERIALS AND METHODS}

The experiment was carried out at the Amano poultry farm, located in the city of Bastos-SP, Brazil and comprised from the first day of life to the production stage (18 th week of age) of commercial laying hens. According to the climatic classification of Köppen, the climate of the region is Cwa, characterized by humid temperate climate, with dry winter and hot summer. All procedures involving the birds were approved by the Ethics Committee on the Use of Animals number 27/2015, of the Faculty of Agrarian and Technological Sciences of Unesp - Dracena Campus.

In the total, 480 laying hens of the Dekalb White line were used, they were housed in Californian type aviaries without air conditioning. In the breeding phase (1 to 6 weeks of age) the birds were distributed in a completely randomized design divided into three treatments: T1- Infrared Radiation (IR) with high intensity of infrared light on the first day still in the hatchery, T2- conventional hot blade debeaking (HB) and T3- $V$ debeaking, both carried out at the eighth day of life, preserving $2 \mathrm{~mm}$ of the nozzle for the IR and $\mathrm{HB}$ debeaking, and for $V$ debeaking $1 \mathrm{~mm}$ from the nasal orifice was preserved, totaling three treatments with 4 replicates of 40 birds / each, housed in 12 cages each measuring $100 \times 80 \times 40 \mathrm{~cm}$ with a density of $200 \mathrm{~cm} / \mathrm{bird}$.

In the rearing phase (6-16 weeks of age of the chickens), 420 birds from the breeding phase were transferred to the rearing shed and redistributed in a completely randomized design, divided into three treatments with 28 replicates with 5 replicate birds / each, housed in 84 cages measuring $50 \times 50 \times 50$ with density of $450 \mathrm{~cm} /$ bird containing 5 birds.

The second debeaking was carried out on the $11^{\text {th }}$ week in the birds debeaked by IR and $H B$, preserving $4 \mathrm{~mm}$ of the nostril, except for the $V$ debeaking.

In the laying phase (16-28 weeks of age of the pullets), 405 birds from the rearing phase were transferred to the laying shed and redistributed in a completely randomized design, divided into three treatments with 27 replicates and 5 birds / each , housed in 81 cages with the same cage size and recreating stage density.

Egg quality parameters were evaluated during three consecutive days on the $28^{\text {th }}$ week corresponding to the maximum production peak, where 27 fresh eggs per day of each treatment were collected, ie $7 \%$ of the total of the eggs, weighing approximately $60 \mathrm{~g}$, measured with the Diamond $₫$ Digital High Precision Scale $(0.1 \mathrm{~g})$ (adapted from Santos et al., 2013).

The analysis was performed with the individual weighing of the eggs and the beaks were cut using appropriate scissors near the tip, that being the narrowest part of the beak. The analyses regarding the egg quality were performed by the Nabel Digital Egg Tester $^{\circledR}$ - (egg weight (WTg), albumen height (HTmm), yolk color (YCT), Haugh unit (HU), bark resistance (kgf)) And shell thickness (thk) - without the membrane). 
Balan JAO, Silva KM,

Polycarpo GV, Iwayama LH
Oka CH, Bueno LGF, Souza SRL,

\section{Performance of Commercial Laying Hen Submitted to} Different Debeaking Methods

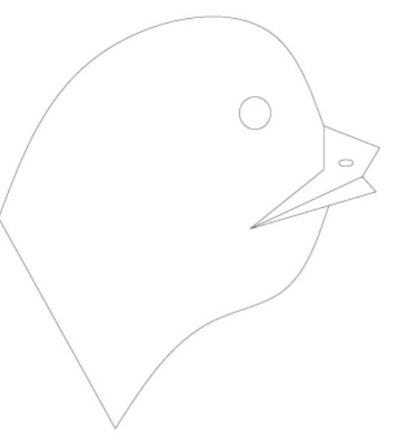

a) $\mathrm{V}$

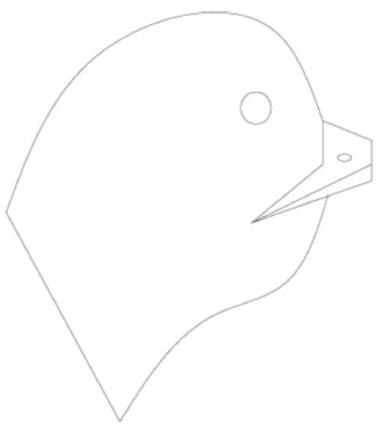

b) Infrared Radiation debeaking three different techniques in different ages were used. For the achievement of the $\mathrm{V}$ debeaking, a Verschuuren ${ }^{\circledR}$ debeaker was used, which performed the cross-section cut, with a blade that has a " $\mathrm{V}$ " format in the center. At the time of the procedure, the blade temperature reached 750 to $800^{\circ} \mathrm{C}$. The birds were bled only at 8 days of age with recommended beak size, $1 \mathrm{~mm}$ from the nasal orifice (Figure 1a). In the V-debeaking, the second debeaking was not carried out.

In the infrared debeaking, the Nova Tech $^{\circledR}$ equipment was used with high intensity $(25$ to $23 \mathrm{~mm}$ high), with high light intensity of $52 \mathrm{~nm}$, performed on the chickens with one day of age still in the hatchery (Figure 1b).

The conventional hot blade debeaking was performed at 8 days of age, seeking the recommended size of the $2 \mathrm{~mm}$ nozzle from the nasal orifice and using the Lyon $®$ debeaker, which performed vertical cutting movements with a straight blade and varying temperature of 750 to $800^{\circ} \mathrm{C}$ (Figure 1C).

The second debeaking was performed at 70 days for IR and HB, with blade temperature identical to the first debeaking, seeking to meet the recommended $5 \mathrm{~mm}$ size from the nasal orifice, according to the guidance of the Dekab White Line management guide.

The debeaking was always carried out in quiet times (between 6:00 a.m. and 7:00 a.m.) of the day and by outsourced and trained staff hired by the farm. Each bird flanked by HB and $V$ was inspected for retouching if necessary at the edge of the beak, cauterizing with the blade if there was bleeding.

The feed and water supply was ad libitum, and the feed was distributed twice a day. In the period from 1 to 4 days of age, this supply was made through front feeders and a baby feeder. From the fourth day of age, the feed distribution was made exclusively through front gutter feeders.

The data were tabulated weekly during the whole experimental period, in the breeding and rearing phase $(\mathrm{G})$, mean weight gain (g), average daily weight gain

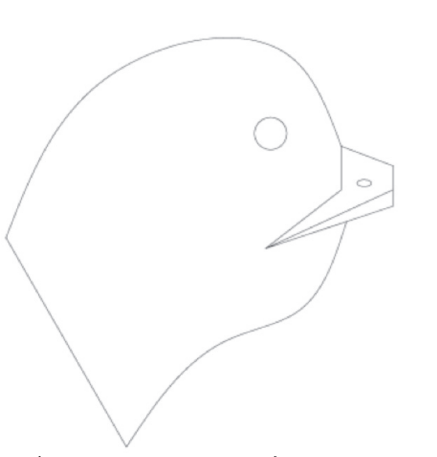

\section{c) Convencional}

Figure 1 - Debeaking Techniques a) V; b) Radiação Infrared Radiation; c) Convencional

(g) weight uniformity (\%), viability (\%), nozzle length $(\mathrm{mm})$, beak uniformity $(\mathrm{mm})$, absence of cannibalism (\%) and mortality.

The number of dead birds was recorded daily for mortality determination in specific spreadsheets. Subsequently for analysis calculated the daily frequency of mortality of birds and employee and the chi-square test.

In the production phase, the following variables were analyzed at the $28^{\text {th }}$ week, corresponding to the peak production: egg weight (WTg), albumen height ( $\mathrm{HT} \mathrm{mm})$, yolk color (YCT), Haugh unit HU), shell resistance (kgf) and shell thickness (thk) - without the membrane for three consecutive days to evaluate differences in egg quality in the three different types of deboning. Feasibility is the difference between the initially housed birds and the withdrawals for deaths calculated as a percentage. Uniformity (equation 1) was calculated using the mean weight in grams $( \pm$ $10 \%)$, thus having the lower and upper limit of the sample. Subsequently, the number of birds that were within the limits established between this interval were verified (Ávila et al., 2007).

Uniformity $=\frac{\{\text { number of birds }( \pm 10 \text { mean weght })\}}{\text { total number of birds in experiment }} \cdot 100 \%$

Statistical analysis of the data was carried out using the statistical software R. The data normality 
Table 1 - Performance of Dekalb White Chicks to different methods and debeaking in the breeding phase.

\begin{tabular}{|c|c|c|c|c|c|}
\hline \multirow{2}{*}{ Variables } & \multicolumn{3}{|c|}{$\mathrm{DEBEAKING}^{1}$} & \multirow[t]{2}{*}{$C V(\%)$} & \multirow[t]{2}{*}{$p$} \\
\hline & $\mathrm{IR}$ & $\mathrm{HB}$ & V & & \\
\hline Average initial weight (g) & 35.20 & 39.31 & 35.54 & 10.3666 & 0.2872 \\
\hline Average final weight (g) & $401.82 a$ & $376.21 \mathrm{ac}$ & $356.12 b c$ & 4.8752 & 0.0205 \\
\hline Average weigth gain (g) & $366.61 a$ & $336.90 \mathrm{ac}$ & $320.58 b c$ & 5.2931 & 0.0167 \\
\hline Average daily weight gain (g) & $8.73 a$ & $8.02 \mathrm{ac}$ & $7.63 b c$ & 5.2926 & 0.0167 \\
\hline Viability (\%) & 91.87 & 88.75 & 89.37 & 7.4362 & 0.7884 \\
\hline
\end{tabular}

Averages followed by equal letters on the same line do not differ statistically (Tukey $p<0.05$ ).

${ }^{1}$ IR - Infrared Radiation; HB - Hot Blade; V-V Debeaking

test was performed and for the data referring to the zootechnical performance the analysis of variance was done and when necessary the Tukey test $(p<0.05)$. Data on cannibalism and mortality (non-parametric) behaviors used the Qui-Square test (95\%).

The uniformity of the nozzle was calculated by substituting the mean weight per $\mathrm{mm}$ of the nozzle $( \pm$ $10 \%$ ), in the same way as the weight uniformity was calculated.

\section{RESULTS AND DISCUSSION}

The results referring to the zootechnical performance and the frequency of mortality of the breeding and rearing phases are presented in Tables 1 to 3 , respectively.

The conventional hot debeaking (Table 1) was statistically similar to the infrared (IR) and $V$ debeaking, which differed from each other for the variables mean final weight $(p=0.0205)$, mean weight gain $(p=0.0167)$ and daily mean weight gain $(p=0.0167)$. This fact was probably due to the stress caused by the severe procedure of the $8^{\text {th }}$ day of life, which caused pain to the chicks. Dennis et al. (2009), did not find statistical differences in the weight gain of the birds and in the weight of the eggs comparing the hot blade deboning and the infrared radiation in their study. The authors report that infrared (IR) deboning results in less aggressive behavior by laying hens.

There is an increase in sensitivity in the beak of the birds after the debeaking procedure. This increase exists due to the damage caused to the mechanoreceptors of the beak that cause the birds to become apathetic and present a reduction in their behavior of food intake (Fahey et al., 2007).

The mean viability of the birds was not influenced ( $p=0.7884$ ) by the type of debeaking. The uniformity at this stage in all treatments remained at 100\%, representing an index within the standard, according to Ávila et al. (2007). Possibly the use of suitable techniques for debeaking, associated with access to water and good quality feed avoided the mortality of laying hens at this stage evaluated (Laganá et al., 2011).

Table 2 - Frequency of mortality among different methods of deboning in the breeding and rearing phases.

\begin{tabular}{|c|c|c|c|c|}
\hline \multirow{2}{*}{ Frequency of Mortality } & \multicolumn{3}{|c|}{ DEBEAKING $^{1}$} & \multirow[t]{2}{*}{$p$ value } \\
\hline & $\mathrm{IR}$ & $\mathrm{HB}$ & V & \\
\hline Breeding & 13 & 18 & 17 & $3.716 \mathrm{e}^{-12}$ \\
\hline Rearing & 1 & 4 & 3 & 0.4169 \\
\hline
\end{tabular}

The mortality in the breeding phase was different among the types of debeaking $\left(p>3,716 \mathrm{e}^{-12}\right)$. Infrared irradiation (IR) showed a lower frequency and better result when compared to hot blade $(\mathrm{HB})$ and $\mathrm{V}$-weighted debeaking. The technique by IR reduced the damage caused by the aggressive feather pecking and according to studies by Denis \& Cheng (2009) would be a more favorable alternative to well-being when compared to conventional debeaking without compromising productivity.

The $\mathrm{V}$-technique is considered to be a severe debeaking, and in the literature high mortality rates are reported when severe debeaking is used in poultry. Pizzollante et al. (2007) evaluated different types of debeaking in Japanese quails, including severe deboning ( $1 / 3$ of the trimmed beak or $1 / 2$ of the trimmed beak), in order to verify if the method could optimize the production and quality of the quail's eggs. They verified that the worst performance occurred with the severe debeaking ( $1 / 2$ of the trimmed beak) with decrease of the zootechnical indexes and increase in the mortality.

In the rearing phase the birds had already recovered from the debeaking procedure and there was no difference between the deboning techniques $(p=0.4169)$. Vieira Filho et al. (2016), found similar results when comparing conventional Hot Blade and Infrared Radiation (IR) debeaking. However, in the study, IR was a viable option when compared to Hot Blade $(\mathrm{HB})$, since it did not alter the productive performance nor the egg quality. 
Table 3 - Performance of Dekalb White pullets, submitted to different deboning methods in the rearing phase.

\begin{tabular}{|c|c|c|c|c|c|}
\hline \multirow[b]{2}{*}{ Variables } & \multicolumn{3}{|c|}{ DEBEAKING ${ }^{1}$} & \multirow[t]{2}{*}{ CV (\%) } & \multirow[t]{2}{*}{$p$} \\
\hline & $\mathrm{Rl}$ & LQ & $\mathrm{V}$ & & \\
\hline Average initial weight(g) & $418.85 a$ & $382.32 b$ & $360.45 b$ & 13.5065 & 0.0003 \\
\hline Average final weight (g) & $1048.85 a$ & $1051.84 a$ & $1104.06 b$ & 5.9431 & 0.0020 \\
\hline Average weigth gain $(\mathrm{g})$ & $3104.28 a$ & $3194.42 a$ & $3592.75 b$ & 15.1751 & 0.0010 \\
\hline Average daily weight gain (g) & $50.59 a$ & $50.70 a$ & $57.02 \mathrm{~b}$ & 13.0299 & 0.0007 \\
\hline Viability (\%) & 99.28 & 97.14 & 97.85 & 7.5377 & 0.5460 \\
\hline
\end{tabular}

Averages followed by equal letters on the same line do not differ statisticallyTukey $5 \%$.

'IR - Infrared Radiation; HB - Hot Blade; V-V Debeaking

Mortality in the rearing phase (Table 3 ) did not present a significant difference $(p=0.4169)$ between the treatments. The cannibalism index was null, since all birds went through the debeaking process, regardless of the type of treatment, and this greatly reduces the rate of cannibalism when observed to the non-debeaked birds.

Vieira Filho et al. (2016) also reports, results similar to not observing cannibalism when not performing the procedure of the second debeaking. It reports that it exerts minimal negative effects on the productive performance of commercial laying hens, as it did not observe frequency of cannibalism among the birds and only the body mass and the length of the beak were altered by the application of debeaking in the rearing. It is noted that modern lineages are less susceptible to cannibalism and feather pecking and are considered to be more docile and adapted to the cage production system (Janezak \& Riber, 2015).

In addition, Laganá et al. (2011), found that birds submitted to debeaking compared to non-debeaked birds showed a quieter behavior, posture rate efficiency and a decrease in mortality rate.

Table 4 - Length of the beak (mm) of Dekalb White pullets subjected to different debeaking methods in the rearing phase.

\begin{tabular}{lccc}
\hline Treatment & Length of the beak $(\mathrm{mm})$ & $\mathrm{CV}(\%)^{2}$ & p value $^{3}$ \\
\hline $\mathrm{IR}$ & $5.88 \mathrm{a}$ & & \\
$\mathrm{HB}$ & $4.56 \mathrm{~b}$ & 9.4857 & $<2 \mathrm{e}^{-16}$ \\
$\mathrm{~V}$ & $3.76 \mathrm{c}$ & & \\
\hline
\end{tabular}

Different letters indicate statistical difference at $5 \%$ of significance by the Tukey test

'IR - Infrared Radiation; HB - Hot Blade; V- Debeaking

It was observed in the rearing phase (Table 4) that infrared (IR) debeaking and conventional hot blade (KB) debeaking provided a reduction in average weight gain and average daily weight gain, reflecting in the final weight average, compared to the $\mathrm{V}$ debeaking. Probably this fact occurred as a consequence of the stress of the second debeaking performed at 70 days. The $V$ debeaking, which eliminates the second debeaking, provided the birds with better results in relation to the others, because although it is a severe debeaking it performs its procedure in a single time reducing the birds' exposure to stress and providing a better recovery with better weight gain.

According to Ávila et al. (2007), V-debeaking causes a lesion on the palate and is recommended in the second debeaking. The single debeaking performed adequately at 8 to 10 days, shows good results and shows low rates of neuromas and deformities in the beak as was verified in the present experiment. These results show that the second debeaking performed for $\mathrm{IR}$ and $\mathrm{HB}$ affected the performance of the birds.

The viability average of the birds was not influenced ( $p=5460$ ) by the type of debeaking, remaining similar for the three methods studied. This result differs from the one found by Vieira Filho et al. (2016), during the $63^{\text {rd }}$ week of life of the birds due to the conventional method of Hot Blade and Infrared Radiation, where they found an $8 \%$ drop in the viability of the lots.

A great gap in the debeaking is in the standardization of the sizes and uniformity of the nozzles. In the rearing phase, a difference was observed between the debeaking methodologies (Table 4). The birds treated by the infrared radiation methodology had a longer beak length when compared to the birds that had the beaks treated by the conventional hot blade debeaking methodology and by the $V$-debeaking method. Since the $V$ technique was not submitted to second Debeaking.

Vieira Filho et al. (2016), observed that birds submitted to second debeaking are lighter, both at the beginning and at the end of the productive period and with smaller beaks than birds that were not submitted to a second debeaking. They also mention that the result of a smaller mass that corporates the beginning of the productive cycle is a reflection of the reduction of the consumption of food of the days that followed of the debeaking process.

These results differ from those found by MarchantForde \& Chen (2010), where the infrared radiation treatment inhibited the growth of the beak in 
comparison to hot blade debeaking, and should be a reflection of the type of line used in the experiment. Carruthers et al., (2012) observed that laying hens of the Lohman strain due to Infrared Radiation (IR) presented smaller beak lengths when compared to Hot Blade (HB) debeaking, corroborating the findings in this study.

Comparing the average values of birds submitted or not to the second debeaking, in the three treatments Infrared Radiation (IR), Hot Blade (HB) and
$V$, it was found that they differed from one another, being the smallest length of the beak for $V$ debeaking $\left(p=<2 \mathrm{e}^{-16}\right)$.

Regarding the uniformity of the nozzle, the $\mathrm{V}$ debeaking and Hot Blade (HB) showed a value of $82.14 \%$ indicating lower uniformity compared to infrared radiation, which presented $92.86 \%$ uniformity.

Table 5 presents the results concerning egg quality in the production phase.

Table $\mathbf{5}$ - Egg quality of laying hens at 28 weeks of age submitted to different deboning methods.

\begin{tabular}{lcccccc}
\hline & WT & HT & YCT & UH & STR & THK \\
\hline Averages $^{1}$ & & & & & & \\
\hline $\mathrm{R}^{2}$ & 56.48 & 6.87 & 11.12 & 79.20 & $3.876667 \mathrm{~b}$ & $0.3819 \mathrm{~b}$ \\
$\mathrm{HB}$ & 57.35 & 7.24 & 11.16 & 82.21 & $4.326296 \mathrm{a}$ & $0.3993 \mathrm{ab}$ \\
$\mathrm{V}$ & 56.39 & 7.53 & 11.14 & 83.51 & $4.651852 \mathrm{a}$ & $0.4085 \mathrm{a}$ \\
\hline Levels of Significance & & & & & \\
\hline$p^{3}$ & 0.57 & 0.699 & 0.986 & 0.747 & $0.0002^{* *}$ & $0.0237^{*}$ \\
$\mathrm{VC}^{4}$ & 6.4355 & 39.6360 & 6.4617 & 25.9663 & 15.5870 & 8.9539 \\
\hline
\end{tabular}

'WT, egg weight (g); HT, albumem height (mm); YCT, yolk color; UH, Haugh unit; STR, Shell resistance; THK, Shell thickness, ${ }^{2} \mathrm{R}$, infrared radiation; HB, hot blade or convencional; $V, V$ debeaking, ${ }^{3} p$ value, ${ }^{4} \mathrm{VC}$, variance coeficient.

The daily fluctuations in air temperature and relative air humidity may interfere with egg quality. For this reason, the hours of collection and weighing of the analyzed eggs were pre-established. Eggs were not observed since the cages were from new and planned constructions with appropriate slope where the birds had no contact with eggs, reducing losses with broken, dirty and cracked eggs.

In the results obtained in this study, for shell thickness (THK), the debeaking $V$ showed better results than the debeaking by Infrared Radiation (IR). However, the Hot Blade debeaking $(\mathrm{HB})$ did not differ from the other treatments ( $p=0.0237$ ) (Table 5). Although $\vee$ debeaking is more traumatic initially, it happens only once, and there is a hypothesis that this new $V$ shape may make the bird less selective, directly reflecting the reduction of feed waste and better use of it, thus justifying the best result. This advantage was only allowed due to the standardization of the cut and trained staff to make the healing process effective. It is worth mentioning that the genetic influence due to the lineage used in association with nutrition with better use added to the age of the laying hens, provided ideal situations for the balance of shell quality.

In the results for shell strength (STR) the infrared (IR) debeaking presented inferior results to the others, showing fragility at the moment of the test. This is due to the process of the second severe debeaking, which caused the decrease in weight as a result of the trauma, directly reflecting the reduction in feed intake during the following 2 weeks, probably affecting the absorption of essential mineral matter for bark formation.

Pizzolante et al., (2007) evaluating variations in poultry debeaking techniques did not find statistical differences in egg shell thickness. The authors explain that the reduction in feed consumption caused by the debeakings did not affect the intake of nutrients that determine the quality of the shell.

No significant difference was observed in egg quality (WT), albumen height (HT), yolk color (YCT) and Haugh unit (HU). A similar result was found by Vieira Filho et al., (2016) and Laganáet al., (2011) when comparing techniques of egg quality and egg quality in poultry farming. Thus the internal egg quality was statistically similar in the production phase. This is probably due to the influence of lineage, age, management and environmental factors.

The average of the $\mathrm{UH}$ variable of the present experiment in the three methods was characterized as excellent according to the Quality Control Program of the American Department of Agriculture, which establishes quality requirements. The WT average was below $60 \mathrm{~g}$ but very close to ideal. This is probably due to the age of the bird and the temperature. However, Figueiredo et al. (2011), found that eggs kept at room temperature presented lower weight than chilled eggs due to the laying age, time and temperature. Laganáet 
Oka CH, Bueno LGF, Souza SRL,

Balan JAO, Silva KM,

Polycarpo GV, Iwayama LH
Performance of Commercial Laying Hen Submitted to Different Debeaking Methods al. (2011), working with Japanese quails submitted to 3 types of debeaking, concluded that the debeaking type did not influence the percentage of albumin and gem. Pizzolante et al. (2007) found that quails severely debeaked ( $1 / 2$ beak) decreased feed intake but did not influence egg quality.

\section{CONCLUSION}

The $V$ debeaking is more invasive in the beginning, but it eliminates the stressful process of the second debeaking, besides providing better results of performance, of resistance and shell thickness when compared to the inflections by infrared radiation and by hot blade.

The frequencies of cannibalism were null among the different debeaking techniques.

Mortality was differentiated in breed, being better in IR debeaking. However in the rearing phase it was equal among the different techniques.

\section{ACKNOWLEDGEMENTS}

The authors would like to thank Granja Amano, in Bastos, SP - Brazil for providing the experiment.

\section{REFERENCES}

Alves PS, Silva IJO, Piedades MS. Avaliação do bem-estar de aves poedeiras comerciais:efeitos do sistema de criação e do ambiente bioclimático sobre o desempenho das aves e a qualidade de ovos. Revista Brasileira de Zootecnia 2007;36(5):1388-1394.

Angevaare MJ, Prins S, Staay FJV, Nordquist RE. The effect of maternal care and infrared beak trimming on development, performance and behavior of silver nick hens. Applied Animal Behaviour Science 2012;140:70-84

Ávila VS, Albino JJ, Saatkamp MG. Método para avaliar a uniformidade nas fases de cria e recria em lotes de frangas para produção de ovos [cited 2017 Mar 22]. Concórdia: Embrapa Suínos e Aves; 2007. (Instrução Técnica, 34). Available from: https://www.embrapa.br/ busca-de-publicacoes/-/publicacao/443610/metodo-para-avaliar-auniformidade-nas-fases-de-cria-e-recria-em-lotes-de-frangas-paraproducao-de-ovos.

Carruthers C, Gabrush T, Schwean-Lardner K, Knezacek TD, Classen HL, Bennett $C$. On-farm survey of beak characteristics in white leghorns as a result of hot blade trimming or infrared beak treatment. Journal of Applied Poultry Research 2012;21(3):645 650.

Dennis RL, Cheng HW. A comparison of infrared and hot blad beak trimming in layin. International Journal Poultry Science 2010;9(8):716719.
Dennis RL, Fahey AG, Cheng HW. Infrared beak treatment method compared with conventional hot-blad trimming inlaying hens. Poultry Science 2009;88(1):38-43.

Fahey AG, Marchant-Forde RM, Cheng HW. Relationship between body weight and beak characteristics in one-day-old white leghorn chicks: its implications for beak trimming. Poultry Science 2007;86(7):13121315.

Fournier J, Schwean-Lardner K, Knezacek TD, Gomis S, Classen HL. The effect of toe trimming on behavior, mobility, toe length and other indicators os welfare in tom turkeys. Poultry Science 2015;94:14461453.

Figueiredo TC, Cançado SV, Viegas RP, Rêgo IOP, Lara LJC, Souza MR, et al. Qualidade de ovos comerciais submetidos a diferentes condições de armazenamento. Arquivo Brasileiro de Medicina Veterinária e Zootecnia 2011;63(3):712-720.

Guesdon V, Ahmed S, Mallet S, Faure JM, Nys Y. Effects of beak trimming and cage design on laying hen performance and egg quality. British Poultry Science $2006 ; 47(1): 1-12$.

Janczak AM, Riber AB. Review of rearing-related factors affecting the welfare of laying hens. Poultry Science 2015;94(7):1454-1469.

Lagná C, Pizzolante CC, Togashi CK, Kakimoto SK, Saldanha ESPB, Alvares V. Influência de métodos de debicagem e do tipo de bebedouro no desempenho e na qualidade de ovos de codornas japonesas. Revista Brasileira de Zootecnia 2011;40(6):1217-1221.

Marchant-Forde RM, Cheng, HW. Different effects of infrared and one-half hot blade beak trimming on beak topography and growth. Poultry Science 2010;89;2559-2564. Available from: DOI:10.3382/PS.201000890.

Marchant-Forde RM, Fahey AG, Cheng HW. Comparative effects of infrared and one-third hot-blade trimming on beak topography, behavior, and growth. Poultry Science 2008;87(8)1474-1483.

Mertens K, Loffel J, DE Baere K, Zoons J, De Baerdemaeker J, Decuypere E, et al. Layers in aviary system:Effects of beak trimming and alternative feed formulation on technical results and egg quality. Journal Applied Poultry Research 2009;18(1):90-102.

Pizzolante CC, Garcia EA, Saldanha ESPB, Laganá C, Faitarone ABG, Souza HBA, et al. Break trimming methods and their effect on the performance and egg quality of Japanese quails(Coturnix japonica) during lay. Revista Brasileira de Ciência Avícola 2009;9(1):7-21.

Silva GF, Pereira DF, Bueno, LGF, Santos TS, Tavares BO. Performance of laying hens and economic viability of different climatization systems. Italian Journal of Animal Science 2013;12(47):286-294.

Vieira Filho JF, Garcia EA, Oba E, Santos TA, Silva AP, Molino AB, et al. Índice produtivo e qualidade de ovos de galinhas poedeiras submetidas a diferentes métodos de debicagem. Pesquisa Agropecuária Brasileira 2016;51(6):759-765. 
